Bol. Acad. peru. leng. 62. 2017 (71-90)

\title{
César Moro y la identidad en conflicto. Simbolismo, psicoanálisis, surrealismo y abstracción en el arte peruano
}

Cesar Moro and an identity in conflict. Symbolism, psychoanalysis, surrealism and abstraction of the Peruvian art

\author{
FERNANDO VILLEGAS \\ Pontificia Universidad Católica del Perú
}

Resumen:

Se busca estudiar los referentes artísticos de César Moro y la importancia de su obra en el desarrollo del arte peruano. Sabemos que Moro conoció la propuesta simbolista legada por José María Eguren, además de familiarizarse con el psicoanálisis en Lima antes de su viaje a París, donde se encontrará con el grupo surrealista. Será en la década de los veinte que manifestará una propuesta vinculada a la abstracción y la geometría cubista. Otro punto importante de este artículo es explorar la identidad de Moro a través de su arte y su propia representación: retratos y fotografías. En ambos evidencia correspondencia tanto en cómo asume ser representado y en cómo realiza sus obras. Nacido con el nombre de Alfredo Quíspez Asín cambiaría su nombre 
por el de César Moro. La adopción de un nombre conlleva la opción de reconocerse artista, forja así una nueva identidad cuya mirada creativa es múltiple. Nos centraremos en cómo quiso ser representado a través del retrato y la fotografía. De este modo se busca entender cómo manifiesta una unidad indiscutible tanto en el proceso creativo del artista como en el texto escrito y la imagen.

\section{Abstract:}

This paper aims to study the artistic references of Cesar Moro and the importance of his work in the development of Peruvian art. We know that Moro met the Symbolism proposal bequeathed by Jose Maria Eguren, in addition to be familiarized with the psychoanalysis in Lima before his trip to Paris, where he would meet the surrealist group. It would be in the twenties when he displayed a proposal linked to the abstraction and Cubist geometry. Another important point of this article is to explore the identity of Moro through his art and his own representation: portraits and photographs. In both, there is a connection of how he assumes to be represented as in how he performed his works. He was born with the name of Alfredo Quispez Asin and he changed to Cesar Moro. The adoption of a new name implies the option to recognize himself as an artist forging a new identity whose creative vision is multiple. We will focus on how he wanted to be represented through portraits and photography. In this way, it is attempted to understand how he manifested an indisputable unit both in the creative process of the artist and in a written text and image. 
Palabras clave: César Moro, arte peruano, simbolismo, psicoanálisis, surrealismo y abstracción.

Keywords: Cesar Moro, Peruvian art, symbolism, psychoanalysis, surrealism and abstraction.

Recibido: 14/09/2016

Aceptado: 15/01/2017

Desde muy joven Alfredo Quíspez Asín revela la necesidad de ser retratado, como lo muestran las obras que le hacen sus amigos y su hermano Carlos. Es consciente de que será artista y de que su retrato, rasgo de su propia personalidad creativa, debe ser perennizado. Esto lo documenta una carta enviada a su hermano que se encuentra estudiando en la Escuela de Bellas Artes de San Fernando en Madrid, fechada el 27 de enero de 1922, en la que hace referencia a un retrato. Aunque desconocemos quién es el autor, Moro describe: «En cuanto pueda te mandaré una fotografía del retrato del que te hablé [...] Oye, reclam(o) el retrato que me ofreciste hacer en Lima» (Moro a CQA, 27 de enero de 1922). Posteriormente mencionaría que fue el artista Emilio Goyburu quien le estaba haciendo un retrato y reclama a su hermano el retrato pendiente: «Goyburu me concluyó el retrato, pronto te mandaré una foto de él. ¿Tú no podrías hacerme uno de memoria? Me lo debes» (Moro a CQA, marzo de 1922). Se decide a enviarle una foto, pero no encuentra quién le pueda prestar una cámara ${ }^{1}$. Además sabemos que Jorge Seoane también le realizó un retrato,

1 Carta de César Moro a CQA del 12 de agosto de 1922 y sería reiterado en otra al mismo destinatario el 29 noviembre de 1922. 
que aparece publicado en Variedades ${ }^{2}$. Moro comprometió a artistas vinculados a los lenguajes modernistas del arte peruano, su propio hermano Carlos Quíspez Asín (CQA), Emilio Goyburu y Jorge Seoane ${ }^{3}$.

El retrato pintado por su hermano se hizo realidad, por medio de una carta Moro comenta que «estaría encantado de ver el retrato que le ha hecho CQA, no ha podido mandarle su retrato fotográfico falta de cámara Seoane le ha ofrecido la suya» (Moro a CQA, 12 de agosto de 1922). En otra carta se confirma que un apunte de su hermano fue mostrado al doctor Hermilio Valdizán, al parecer el retrato de Moro (Moro a CQA, 28 de agosto de 1922).

En este período la corriente que influencia su obra es el simbolismo. Moro frecuentaba la casa del poeta José María Eguren, artista simbolista que fue la primera influencia del joven Alfredo Quíspez Asín en el desarrollo de un arte de vanguardia (Tarazona 2005: 314-315). En ese sentido, tenemos que precisar que los referentes que reconoció en Eguren no fueron exclusivamente poéticos sino plásticos, entendiendo que antes que la mirada poética tenía una inclinación por desarrollar la pintura y la danza (Freire 1998: 37)4. La primera lo acompañaría hasta su muerte, la segunda terminaría en París por una enfermedad. Esto lo comprobamos al comparar varias acuarelas simbolistas realizadas por

2 Sobre este retrato Moro diría en una carta: «Seoane me ha hecho un retrato a tinta china, lindísimo, es de tamaño pequeño» (Moro a CQA, 4 de septiembre de 1922).

3 Estos artistas serían los que en la segunda década del siglo XX propondrían el desarrollo del arte peruano relacionado con las vanguardias artísticas, esto se evidencia en la gráfica artística.

4 Westphalen aclara que tanto poesía como pintura fueron a la par en los trabajos iniciales de Moro (1969: 54). 
Eguren que encuentran correspondencia con la obra del joven artista.

Hay aspectos semejantes en la representación de seres apenas abocetados y con aire fantasmal que aparecen insertos en un paisaje bucólico, es el caso de una acuarela de Eguren comparada con Sin título ${ }^{5}$, de Moro. Además, otra obra del poeta barranquino muestra diseños geométricos al realizar una casa con un personaje que tiene como fondo un edificio. Esto guarda relación con Sin título ${ }^{6}$ de Moro donde, a manera de retablo, se inscribe una forma con una cabeza en gris. Lo que nos llama la atención es la disposición geométrica en ambas, el marcado trazo ampuloso. Una pareja durmiendo y sentada frente a una mesa donde aparecen insectos de Eguren, si bien Moro no tiene referentes directos, sí puede servir de inspiración para un sinnúmero de personajes que Moro recrearía vinculados a formas de insectos como Sin título (circa 1940) ${ }^{7}$.

También se conoce que frecuenta el Hospicio de la Madgalena y que gracias a Hermilio Valdizán y Honorio Delgado, discípulo de Freud, conoce de psicoanálisis. La tesis doctoral del último, Rehumanización de la cultura científica por la psicología (1923), presentada en la UNMSM, insistía en la posibilidad de explorar el inconsciente en el proceso creativo (Villegas 2016: 325326), así, en este período, cuando se le preguntó a Moro

5 Témpera sobre papel, 17, 5 x 19,5 cm, Tenerife Espacio de las Artes, excoleción de André Coyné.

6 Témpera sobre papel, 25 x 15,5 cm, reproducido en el catálogo César Moro retrospectiva de la obra plástica, 2-12 julio 1990, Galería L'Imaginaire como la fig. 5.

7 Témpera sobre papel, 25,5 x 16 cm, Getty Institute, EE. UU., excolección de E. A. Westphalen. 
de dónde salían sus dibujos, el propio artista respondió que él mismo desconocía el porqué de las imágenes. Al respecto nos dice:

[...] cualquier dibujo, por más malo que sea, no es más que producto de mis emociones de artista. Para mí son como interrogaciones, como protestas contra la vida y contra todo. Lo que está al nivel de su cabezota. Más contento estoy cuando aparentemente más incoherente es uno de mis dibujos. Un dibujo no es una confesión. Al contrario, yo mismo no podría explicar mi dibujo. Lo siento y junto conmigo lo sienten dos o tres y con eso me basta (Moro a CQA, 4 de marzo de 1922).

Al decir estas palabras Moro señala que no es consciente de la realización de sus obras y que sus dibujos están determinados por un acto automático e inconsciente, que serían posteriormente vinculados al surrealismo. En este período busca exponer en Lima, en donde las pocas galerías que existen le niegan un espacio alegando que todo está ocupado: «Hace [...] dos años que quiero hacer mi exposición, he recorrido todos los sitios posibles, en todos he recibido la misma negativa con la misma disculpa "No tenemos sitio" "lo sentimos mucho"» (Moro a CQA, 9 de julio de 1924).

Por este tiempo intenta estudiar por lo menos un año en la Escuela de Bellas Artes, actividad que no llega a concretar. En este período hace ilustraciones para algún joven poeta que le pide a manera de favor ayuda en la ilustración de la portada de su libro o para la revista Variedades, actividad no remunerada, por lo que no cuenta con los recursos para realizar sus obras, las que se reducen a tinta, dibujo o acuarelas. Sin dinero es difícil pintar al óleo. 
En el joven Alfredo Quíspez Asín se reconoce una personalidad narcisista. Como artista conoce su capacidad creativa y sabe que no se encuentra en el mejor lugar para desarrollarla. Sobre Lima y su ambiente diría: "Lima es la ciudad de los idiotas, vivo entre idiotas» (Moro a CQA, 29 de noviembre de 1922). Pero hay otro aspecto además que limita el libre desarrollo de su creatividad, es su opción sexual, ser gay y vivir en una sociedad conservadora como la limeña. Se advierte entonces una identidad en conflicto y una ávida necesidad de liberación implícita tanto en su poesía como en su obra gráfica. Ese proceso implica un rechazo a su propio nombre, a su propio idioma, y revela su necesidad de enunciarse de otra manera. En definitiva: de volver a nacer o reinventarse de acuerdo a su verdad. No es lo que la sociedad le pide ser, sino lo que él quiere y decide ser. Fátima Mernisi en Sueños en el umbral refiere que "cuando alguien se halla en una situación desesperada, lo único que puede hacer es cambiar el mundo, transformarlo según sus deseos y volver a crearlo» (1996: 162). Y es lo que hizo Moro al asumir su nuevo nombre, no solo evadió lo que le exigía la sociedad conservadora limeña, sino que liberó su posibilidad de ser quien él quería ser: artista. El arte como vocación, como renuncia, como proceso creativo en libertad ${ }^{8}$.

En 1923 una carta dirigida a su hermano Carlos, que se encuentra en Madrid, da cuenta de la adopción

8 Concordamos con Mirko Lauer cuando analiza la poesía de Moro frente a la realidad restrictiva peruana. Al respecto nos dice: «Pienso que a pesar de la amistad con el idioma francés y de los amigos mexicanos, en ninguna parte fuera del Perú pudo, puede, César Moro ser César Moro, es decir, no ser César Alfredo Quíspez Asín y poder realizar el surrealismo tal como lo describe Theodor W. Adorno: una dialéctica de la libertad subjetiva en una situación de no-libertad objetiva» (1990: 142). 
del nombre César Moro9 ${ }^{9}$ No se trata de un seudónimo sino de la adopción de una nueva identidad. No se sentía cómodo como Alfredo Quíspez Asín y ante la necesidad de reinventarse crea a César Moro. En términos psicoanalíticos, necesitaba matar al padre renunciando a su nombre y apellido. La oposición paterna no significó, sin embargo, una ruptura con su madre, de quien sí conserva el apellido Mas ${ }^{10}$. El nuevo nombre que asumió desde esa fecha fue comunicado a su familia; además, se advierte cuando fue exiliado a México por apoyar a la República española en 1936. El nombre figura también en su libreta de inscripción en el registro nacional de extranjeros.

Podemos entender entonces cómo la construcción de su obra refleja un constante encuentro consigo mismo, donde los lenguajes artísticos y poéticos son miradas exploratorias de su propia esencia vital. Es decir, no se supedita a la moda sino que se adapta a sus circunstancias y no le gusta encontrarse dogmatizado. Ello conlleva que desde lo visual sea difícil situarlo solo en el surrealismo. Desde sus inicios transita en los lenguajes del modernismo, el simbolismo, el cubismo, la figuración lírica, el dadaísmo, para finalmente convertirse en el primer artista que aborda el arte no figurativo en el arte peruano. En sus obras encontramos

9 Por carta de Moro a CQA del 6 de septiembre de 1923 se conoce el cambio de nombre por César Moro, tomado de las greguerías de Gómez de la Serna (Palomino 1986: III-IV).

10 La relación con la madre sería bastante estrecha, incluso decisiva para su regreso de México. Cuando Moro falleció, la familia estaba preocupada por la madre y cómo darle la noticia de su muerte. La madre de Moro no le superviviría mucho tiempo, pocos años después de su muerte fallecería. 
incluso una mezcla de estos estilos y vemos cómo estos se superponen en el tiempo.

Es notable advertir que existe en el artista una coincidencia en cómo decide ser representado en sus retratos y los estilos artísticos y vitales en los que se encuentra. Hacia 1925 Moro decide irse a París a buscar lo que anhelaba: desarrollar el arte de la pintura y el ballet. Antes de viajar se toma una fotografía que muestra las características de la obra que realizaba entonces, en el rostro las cejas aparecen oscurecidas y manifiesta un personaje andrógino casi femenino. Esta mirada es propia del tipo de imágenes vinculadas al decadentismo, práctica que el propio Moro realizaba en su obra gráfica de entonces siguiendo la influencia del español Beltrán Masses. La fotografía está dedicada a Carlos Raygada y fechada en 1925.

Moro, por tanto, llevará a París su conocimiento del simbolismo a través de Eguren y la gráfica modernista de las revistas ilustradas. Su correspondencia con el psicoanálisis, su nueva identidad, lo preparó para ingresar en las filas surrealistas. La inserción en el ambiente parisino no fue fácil para el peruano, sabemos de la carestía económica que tuvo que afrontar (Moro a CQA, 7 de mayo de 1926). Se conoce por una carta a su madre que estudiaba ballet y que se encontraba bien, aunque especulamos que por ser su madre posiblemente omitió sus penurias para no alarmarla (Moro, 20 de julio de 1928).

El lenguaje cubista estaría relacionado con su encuentro con la obra del pintor Jaime Colson, a quien conoció en París por recomendación de su hermano Carlos. Así, Moro compartió sala con el pintor 
dominicano en la exposición en el Gabinete Maldoror (1926) de Bruselas y la Asociación París-América Latina (1927) en París. Un elemento importante en su obra fue la adopción de un lenguaje de formas geométricas presentes en la última exposición. Lo interesante es cuando vemos al propio Moro fotografiado en el taller de Colson, formando parte de una composición cubista. Se ve al artista sosteniendo una guitarra que está rodeada de distintos marcos y cuadros colocados en planos de formas cuadrangulares. La fotografía y la composición insertan a Moro en una obra cubista que corresponde a la propia propuesta creativa de entonces conocida como Géométrie ${ }^{11}$. En este período vio los cien diseños realizados por Pablo Picasso, presentados en la galería de Paul Rosenberg en París entre junio y julio de $1927^{12}$. La importancia de este encuentro se puede apreciar cuando escribió el prólogo de la Exposición Internacional del Surrealismo (1940), que realizó junto con André Breton y Wolfgang Paalen en México D. C. Allí Moro diría: «[...] hacia 1910, fecha histórica en la que Pablo Picasso, el incomparable, inicia su búsqueda designada con el impropio nombre de cubismo. El milagro comenzado, entonces no termina ni con el duro interregno, con el voraz espacio de tinieblas de la Gran Guerra» (Moro 1940: s/n).

Si bien sabemos que el lenguaje cubista en Moro intentaría ser superado cuando participó en París en la

11 Ver catálogo de la exposición Tableaux de Jaime Colson et César Moro, 10 al 16 de marzo de 1927, Sociedad París-América Latina.

12 Aunque la mayoría de obras expuestas por Picasso corresponden a los años 19161926, por tanto, no es su período cubista; sin embargo, sería un artista referente para su propia obra, ya que conservó el catálogo de la muestra. Ver Archivo de TEA. 
Figuración Lírica Española (1927) (Villegas 2016: 328332), también queda claro que nunca abandonó ese lenguaje y que fue retomado cuando incursionó en la abstracción desde su estadía en México y a finales de su vida teniendo una impronta geométrica.

Es reciente el peso y la importancia que ha tenido Moro en el estudio de las artes visuales y su relación con el surrealismo ${ }^{13}$. Hoy es indiscutible la importancia que tuvo al realizar la primera exposición surrealista en América Latina en 1935, en la galería Alcedo, junto con un grupo de pintores chilenos. Su casi ausencia en el panorama de la historia del arte peruano se debe a ser considerado un diletante (Castrillón 2014: 42), opinión no compartida, ya que a pesar de no contar con una formación académica y realizar sus obras en dibujos, acuarelas y pasteles, sus propuestas creativas enuncian la vanguardia y sus lenguajes más que los artistas académicos. El hecho de asumir materiales no oficiales y no estar supeditado a una escuela le otorgó más libertad creativa en sus obras. Moro fue el primer artista surrealista peruano en contacto directo con la vanguardia parisina y el primer latinoamericano en participar en el grupo de André Breton (Ades y Speranza 2012: 16).

El viaje a México le permitió al artista distanciarse del surrealismo y adoptar la tendencia a la abstracción de su última producción en el medio peruano. No es del todo cierto que la abstracción de Moro fue realizada ya en el Perú, porque obras en México como Imágenes cretinizantes (México, 1943) y sobre todo El baño

13 Un reciente trabajo editado por Rita Eder Dawn Ades y Graciela Speranza (2012) lo coloca como el principal referente del surrealismo en Latinoamérica. 
del insecto hoja (México, 1942) ${ }^{14}$ muestran que ya en la ciudad azteca realizaba un tipo de abstracción que podría vincularse al automatismo de André Masson, de formas abstractas y redondeadas alternadas con figuras geométricas ${ }^{15}$, como Pasiphae o Sedeed Sed, ambas realizadas en 1942. El pintor surrealista había lamentado en la década del cuarenta la prevalencia de la irracionalidad automática y el rechazo al cubismo, así nos dice:

El retroceso tuvo lugar con perfecta insolencia. Los admirables logros de Seurat, Matisse y los cubistas fueron considerados como vacíos y sin valor. Su inspirada concepción del espacio, su hallazgo de los medios esencialmente pictóricos, fueron considerados como un legado molesto que era necesario olvidar (Chipp 1995: $465)^{16}$.

Fue en México que Moro se distanció del surrealismo, y fue la abierta oposición de Breton a la homosexualidad lo que marcó la distancia de Moro. En la misma

14 Ambas obras fueron reproducidas en Las Moradas.

15 Las reflexiones de Masson fueron publicadas en Fontine (Argel), Nº 35, 1944, ahí diría: «Se habla mucho sobre la abstracción al referirse a la pintura contemporánea. No sé hasta qué punto deciden los críticos dónde comienza o dónde termina una obra de arte. Quizá un pintor puede sugerir que este término de "abstracto" ha de reservarse para discusiones metafísicas: un terreno en el cual esta idea —se halla aquí como en su casa- ha dado origen a brillantes controversias, desde Aristóteles hasta Husserl y Whitehead.

La ausencia de tema —el cuadro considerado en sí mismo como un objeto- es una estética perfectamente defendible. Sin embargo, el temor de los pintores que así lo proclaman, el miedo a referirse al mundo exterior, tiene un curioso paralelismo con el de quienes no admiten compromiso alguno con lo irracional [...] No basta dibujar o pintar unos cilindros o unos rectángulos ordenados de cierto modo para situarse fuera del mundo» (Chipp 1995: 468-469).

16 Tomado de André Masson. «La pintura como apuesta», 1941, publicado como «Piendre est un gageure», en Cahiers de Sud, No 233 (marzo 1941) (Chipp 1995: 464). 
exposición se percibieron las diferencias entre ambos, cuando Breton incluyó la pintura del mexicano Diego Rivera, más por cuestiones políticas que por praxis artística. La obra de Rivera no era del gusto del peruano y sobre él diría con desenfado:

He visto algunos frescos de Rivera en la Secretaría de Educación, son horribles, de un color atroz y del dibujo convencional que ya conocemos. No es sorpresa, pues jamás me gustó esta pintura y cada día me gustará menos la tal pintura mural (Moro a CQA, México, 11 de abril).

Por otro lado, tendríamos que entender la influencia que ejerció Paalen en el concepto del valor totémico del mundo precolombino que permitió a Moro reencontrarse con la memoria inconsciente del Perú antiguo. En este aspecto concuerdo con Rodrigo Quijano cuando refiere:

La actitud de Moro hacia lo local reposó más bien en una reivindicación prehispánica con la cual sintió una filiación especial, fruto de una vinculación afectiva con el paisaje costeño y fruto tal vez del interés general hacia lo que el surrealismo llamó «culturas mágicas», membrete amplio en el que fueron subsumidas todas las culturas no europeas (2003: 92).

Precisamente en el retrato que le realizó el austriaco (1940), donde se advierte a Moro de perfil y con una actitud introspectiva ${ }^{17}$, se observa a un Moro con arrugas y con la frente mucho más amplia. La pintura

17 El retrato se encuentra autografiado, dice «a César Moro son ami Wolgang Paalen/ México/ 1940». 
guarda relación con su fotografía tomada en la Huacachina en Ica (1948-1950 aproximadamente $\left.{ }^{18}\right)$, donde se mostraba desnudo con todo el cuerpo y el rostro cubierto de barro, la actitud nos recuerda también el retrato realizado años atrás en México.

A diferencia de los artistas peruanos de los primeros años del siglo XX, como Teófilo Castillo, José Sabogal o Elena Izcue, quienes exploraron el lenguaje plástico de la cerámica nasca, moche o los mates o keros, Moro exploró lo que años después se llamaría ancestralismo. Es decir, además de recuperar el lenguaje formal, buscó recuperar su pasado mítico. Esta idea remite a una carta de Honorio Delgado, discípulo de Freud y en ese entonces psicoanalista confeso, dirigida al músico Alfonso de Silva en 1922, en la que refiere que se pondrá: «[...] enseguida a trabajar en mis estudios de la mortalidad [...] de los antiguos peruanos, totemismo, mitología etc. que va a ser tomada en mi comunicación al próximo congreso psicoanalítico de Berlín» (1922: 4).

Tanto Honorio Delgado como Alfonso de Silva eran cercanos a los hermanos Quíspez Asín. Silva, poseedor de la carta de Delgado, visitaría a Moro en París hacia 1925. No obstante, hasta el momento no hemos encontrado en los años veinte una obra artística vinculada al Perú antiguo salvo el collage que realizó en los años treinta, donde representó una cabeza precolombina tal como Adorée au grand air (l'art de

18 Las fechas aproximadas de la foto están determinadas por la relación con André Coyné, que duró entre 1948 a inicios de 1950. Llegamos a esta conclusión porque existe otra foto de Coyné en la que aparece en Ica, lugar de donde proviene la foto de Moro (Coyné 2003: 166). 
lire l'avenir) (1935) ${ }^{19}$. Después de ello esta mirada al mundo del Perú antiguo apareció solo como referencia de exposiciones o textos realizados por Moro. En la muestra surrealista de México se exhibieron obras del arte del México antiguo compuestas por la colección de Diego Rivera y arte oceánico de la colección de Paalen (Quijano 2003: 92). En la revista Las Moradas (1945-1947) la cerámica del Perú antiguo era denominada como arte.

El retorno a Lima desde México en 1943 lo hizo Moro gracias al apoyo económico de su hermano Carlos y a solicitud de su madre ${ }^{20}$. No obstante, vemos que antes de su llegada Moro siente renacer las mismas inquietudes que tenía en sus años juveniles.

No tengo el menor deseo de ir a Perú, pero tratándose de mi mamá que así lo desea y dice que le hago falta he decidido regresar, tú que has vivido tantos años fuera me has de comprender perfectamente. No es egoísmo es instinto de conservación y terror a volver a vivir todos los complejos infantil(es), el terrible complejo de inferioridad frente a la hostilidad del ambiente, frente a los testigos de la infancia (Moro a CQA, México, 5 de mayo de 1943).

Fernando de Szyszlo refiere que el año 1947, fecha de fundación de la revista Las Moradas realizada por Moro y Westphalen, «fuimos por primera vez contemporáneos de todos los hombres» (2002: VII). Creemos además que la revista fue la única vía por la que la obra

19 Collage sobre papel de lija, 13 x 21 cm, excolección E. A. Westphalen, Getty Research Institute.

20 La decisión la toma porque su madre lo extrañaba. 
de Moro y su pensamiento fue recogido por la nueva generación de artistas peruanos como Jorge Eduardo Eielson $^{21}$ o Fernando de Szyszlo.

En la muestra póstuma de Moro, realizada por André Coyné, Fernando de Szyszlo y Carlos Quíspez Asín en 1956 (Coyné 2003: 168), se cumplió el deseo del artista que había preparado una serie de pasteles que evidenciaban la geometría abstracta ${ }^{22}$ de su última etapa y con ello su alejamiento definitivo de las filas surrealistas. También estuvieron presentes los retratos realizados a Moro por Henry Hannot, Carlos Quíspez Asín y Wolfgang Paalen. Szyszlo, el encargado de hacer la presentación, refirió: «Utilizó para expresarse las herramientas que su época había conquistado (el surrealismo, hacia el final la pintura no figurativa) pero siempre tales herramientas estuvieron a su servicio y no a la inversa» (Szyszlo 1956 catálogo homenaje).

Llama la atención la correspondencia que existe en los tempranos trabajos de Szyszlo con la obra de Moro. Esto se observa en el retrato presentado por Szyzslo en Las Moradas, Lima, I, No 1 (mayo de 1947), obra que guarda relación con un retrato $\operatorname{Sin}$ título ${ }^{23}$ de Moro en la prevalencia del uso de la línea para construir la figura del rostro. Szyszlo heredaría de Moro la

21 La importancia de Las Moradas en la obra temprana de Jorge Eduardo Eielson se puede consultar en la tesis de maestría en Historia del Arte, PUCP, de Carlos Castro (inédita).

22 Rodrigo Quijano refiere que Moro no participó en la polémica entre figuración y abstracción que tuvo como protagonistas antagónicos a Sebastián Salazar Bondy y Luis Miró Quesada Garland (Quijano 2003: 92-94). Creemos que sí asumió una posición en su propia obra visual.

23 Pastel y lápiz de color sobre papel, 33,8 x $22 \mathrm{~cm}$, excoleción Westphalen, Getty Research Institute. 
beligerancia contra el tema indigenista de Sabogal y su escuela y la opción del mundo precolombino como pasado mítico vivo.

La independencia creativa y la necesidad de volver al propio lenguaje de la pintura lleva a Moro a relacionarse con las prerrogativas del arte moderno, aquellas que abogaban por el «no tema» y el presupuesto del arte por el arte. La pintura tenía que recuperar su propio lenguaje: la estructura y la composición, dos aspectos importantes para su hermano Carlos, que había emprendido la campaña desde el lenguaje cubista ${ }^{24}$ en la Escuela de Bellas Artes, donde ingresó como profesor en 1943. Esto se hace evidente en una carta enviada desde México, donde se aleja del lenguaje de Sabogal mal entendido como la supeditación al tema:

él (Moro) es incapaz de dibujar una silla y eso le desanima terriblemente. Además, en los últimos años he visto que la pintura es al mismo tiempo que muy complicada, de ejecución, algo muy simple. Quisimos que significara demasiadas cosas ajenas a ella y ahora veo que una simple naturaleza muerta o una mujer sentada en una silla han sido los temas eternos de los más grandes pintores: Renoir

24 «Los maestros franceses modernos nos lo recordaron después de largo tiempo de olvido; y a los cubistas, podemos decir, debemos la rehabilitación de la plástica. Todos dicen que el cubismo ha pasado. Y es cierto; pero a mi modo de ver lo ha hecho dando el paso más grande en el sentido técnico: devolviendo la pintura al campo de la plástica. Y que también ha de servir de disciplina inicial y llamado constante a los actuales futuros pintores. ¿Por qué pasó el cubismo y no se comprendió entonces, ni se comprende todavía en nuestro medio? Sencillamente, porque se desconoce esto que podemos llamar el idioma de la plástica. Así tampoco ha podido comprenderse verdaderamente ninguna otra tendencia o época de la pintura. Este es un idioma sin palabras, su alfabeto es la geometría, por esto es tan mal traducido por los que saben escribir cualquier otro idioma. Tan poco traducible, mejor dicho» (Carlos Quíspez Asín. Los pintores y las pinturas, 4 de octubre de 1945). 
o Picasso o Cézanne o ahora Bonnard, etc. La pintura es una especie de gran cocina. El que no es cocinero y buen cocinero no puede hacer nada. Matisse es un cocinero de primer orden, un gran cocinero. Ahora todos los programas me aburren soberanamente y la intención que ponga el pintor me deja totalmente indiferente [...] ¿Cómo salió Sabogal de ahí? Esta última noticia me produjo regocijo sobre todo después de su triunfo (i) en México. No me explico el caso de Sabogal pintando ya desde hace medio siglo y tan ajeno y contrario siempre a la pintura. A ver si un día pongo en un sobre algún dibujo de los que he hecho últimamente y te lo envío. Tú fuiste la primera persona y estoy por creer que la última que diste importancia a lo que hacía (Moro a CQA, 20 de octubre de 1947).

Moro se convierte en el primer artista vinculado al surrealismo plástico, su derivación a la abstracción geométrica sería un referente para el arte peruano, y Las Moradas, revista instituida por él y Westphalen, un caldo de cultivo de sus ideales. Sin él no podemos entender las propuestas de Eielson o Szyszlo, quienes como el artista no supeditaron su obra a un lenguaje local a favor de un universalismo. Además de su necesidad de trabajar la pintura desde su propio lenguaje, siguiendo la influencia de su hermano Carlos Quíspez Asín desde el cubismo. Tal vez no debemos mencionar que su identidad está en conflicto, si no que busca desarrollarse en un medio que lo subvierte y lo vuelve anárquico. La gestación de su personalidad artística en Lima la horrible convierte su obra tanto poética y plástica en contestataria, reflejo de su propio deseo y necesidad de libertad creativa. En Moro se cumple la frase: nadie es profeta en su tierra. 


\section{Bibliografía}

ADES DAWN, Eder Rita y Graciela SPERANZA. Surrealism in Latin America: vivísimo muerto. London, Tate Publishing, Getty Research Institute, 2012.

CASTRILLÓN, Alfonso. Tensiones generacionales. Lima, Fondo Editorial de la Universidad Ricardo Palma, 2014.

CHIPP, Herschel B. Teorías del arte contemporáneo. Fuentes artísticas y opiniones críticas. Madrid, Ediciones Akal, 1995.

COYNÉ, André. «Moro en sus días y una reciente biografía», en Hueso Húmero. N $^{\circ}$ 43. Lima, 2003, págs. 161-168.

FREIRE SARRIA, Luis. «El Moro del Sherezade», en Mira, El Sol. 1998, págs. 36-38.

LAUER, Mirko. «Razón y pasión en Moro», en Hueso Húmero. No 27. Lima, 1990, pág. 142.

MERNISI, Fátima. Sueños en el umbral. Barcelona, El Aleph, 1996.

MOLINA, César Antonio. «César Moro rompecabezas ejemplar» entrevista a André Coyné. Diario 16. 26 de enero de 1986, págs. III-V.

QUIJANO, Rodrigo. "Con los antejos de azufre: notas sobre Moro y las artes visuales», en Martín. No 7 y 8. Lima, 2003, págs. 185-196.

SZYSZLO, Fernando de. "Las Moradas de Emilio Adolfo Westphalen (testimonio de parte)», en Las Moradas, edición facsimilar. Lima, Universidad San Martín de Porres, Ausonia S. A., 2002, págs. VII y VIII.

TARAZONA, Emilio. «César Moro: notas sobre poesía, plástica y vanguardia en el Perú», en Actas del Coloquio 
Internacional César Moro y el Surrealismo en América Latina. Lima, Fondo Editorial de la UNMSM, 2005, págs. 311-324.

VILLEGAS, Fernando. Vínculos artísticos entre España y el Perú (1892-1929). Elementos para la construcción del imaginario nacional peruano. Lima, Fondo Editorial del Congreso, 2016.

WESTPHALEN, Emilio Adolfo. «Pinturas y dibujos de César Moro», en Amaru. No 9. Marzo, 1969, págs. 53-59. 